\title{
Reproductive Hormone Profiles and Their Relationships with Sexual Function in Patients with Prostate Cancer after Rapid Prostatectomy in Benin City
}

\author{
Babatunde Ishola Gabriel Adejumo ${ }^{1 *}$, Omolei Lilian Williams' ${ }^{1}$, Efosa Bolaji Odigie1, \\ Ifeoma Gloria Unachukwu', Oladimeji Nasiru Abdulrahman², Uchechukwu Dimkpa ${ }^{3}$, \\ Simon Uzor ${ }^{4}$, Oyarazi Margaret Adebowale ${ }^{5}$, Ojo Moses Oke ${ }^{6}$ \\ ${ }^{1}$ Department of Medical Laboratory Science, University of Benin, Benin, Nigeria \\ ${ }^{2}$ Department of Medical Laboratory Science, College of Health Technology, Ilorin, Nigeria \\ ${ }^{3}$ Department of Human Physiology, Nnamdi Azikwe University, Nnewi Campus, Awka, Nigeria \\ ${ }^{4}$ Department of Applied Science, Faculty of Health and Applied Sciences, University of West of England, Bristol, UK \\ ${ }^{5}$ Department of Virology/Immunology, Federal School of Medical Laboratory Science, Jos, Nigeria \\ ${ }^{6}$ Department of Medical Laboratory Science, College of Health Technology, Akure, Nigeria \\ Email: ^babatunde.adejumo@uniben.edu, `bigadejumo@yahoo.com
}

How to cite this paper: Adejumo, B.I.G., Williams O.L., Odigie, E.B., Unachukwu, I.G., Abdulrahman, O.N., Dimkpa, U., Uzor, S., Adebowale, O.M. and Oke, O.M. (2020) Reproductive Hormone Profiles and Their Relationships with Sexual Function in Patients with Prostate Cancer after Rapid Prostatectomy in Benin City. Advances in Sexual Medicine, 10, 119-130. https://doi.org/10.4236/asm.2020.104008

Received: July 28, 2020

Accepted: October 27, 2020

Published: October 30, 2020

Copyright ( 2020 by author(s) and Scientific Research Publishing Inc. This work is licensed under the Creative Commons Attribution International License (CC BY 4.0).

http://creativecommons.org/licenses/by/4.0/ (c) (i) Open Access

\begin{abstract}
There are limited studies examining the relationship between serum reproductive hormone levels and sexual functions among prostate cancer ( $\mathrm{PCa}$ ) patients after rapid prostatectomy (RP). Aim: The present study aimed at evaluating the correlation between post-operative serum levels of some male reproductive hormones of $\mathrm{PCa}$ patients and their sexual functions in the months following RP. A total of 20 male patients with clinically localized PCa who had undergone RP within the last 12 months prior to commencement of the study, were invited to participate. The postoperative serum levels of their luteinizing hormone ( $\mathrm{LH})$, follicle stimulating hormone (FSH) and total testosterone $(\mathrm{Te})$ were measured. They also completed a structured health and lifestyle questionnaire to obtain information on their demographic characteristics and detailed medical history. Our data indicated normal mean levels of post-operative Te $(4.34 \pm 4.38 \mathrm{ng} / \mathrm{ml})$ in the patients following RP, while the mean levels of FSH $(39.24 \pm 34.12 \mathrm{miu} / \mathrm{ml})$ and $\mathrm{LH}(21.67 \pm 25.73 \mathrm{miu} / \mathrm{ml})$ were on the increase and far above normal ranges for healthy men. Data indicated a significant positive correlation between Te and frequency of sexual intercourse $(\mathrm{r}=508 ; \mathrm{p}<0.05)$, libido $(\mathrm{r}=0.429 ; \mathrm{p}<0.05)$ and penile erection $(\mathrm{r}=0.494 ; \mathrm{p}<0.05)$. However, no significant correlations were found between FSH or LH and any of the sexual function parameters. The present
\end{abstract}


study indicated that radical prostatectomy affected reproductive hormones by increasing $\mathrm{LH}$ and FSH concentrations above normal ranges for healthy men, while Te concentrations remained within normal range in the months following RP. The postoperative serum total Te concentrations of the patients were significantly associated with their postoperative sex drive, penile erection and frequency of sexual intercourse.

\section{Keywords}

Reproductive Hormone, Sexual Function, Prostate Cancer, Rapid Prostatectomy

\section{Introduction}

Prostate cancer (PCa) is the second most frequent cancer diagnosis made in men and the fifth leading cause of death worldwide [1] [2]. Sexual dysfunction is a common consequence of not only the prostate cancer itself, but also the various PCa treatment options. Prostate cancer has been linked to reduced sexual desire (libido) and frequency of sexual intercourse [3]. However, the sexual dysfunction is not caused directly by PCa, but a growing prostate tumor can cause severe lower urinary tract symptoms, such as prostate hypertrophy, which could lead to decrease in sexual function [3]. Psychological instability and depression caused by the occurrence of the cancer, its diagnosis, the biopsy and preoperative anxiety can also lead to a sudden reduction in sexual function in patients with PCa [4] [5]. In addition, PCa treatments including surgery, radiation therapy and hormone therapy, can affect various aspects of male sexual function, including libido, penile erection and frequency of sexual intercourse.

Prostate cancer surgery involves the removal of the entire prostate gland (radical prostatectomy). This treatment option is generally offered to men with localized PCa and in some instances, to men with locally advanced PCa [6]. It remains the most important treatment method for local PCa despite the development of other endourological treatment techniques such as endoscopy or robots. After surgery, all men will experience loss of ejaculation, because the organ responsible for ejaculation has been removed [7]. Orgasm quality is adversely affected in many men since semen is no longer produced due to the removal of the seminal vesicle [6] [7]. Erectile dysfunction is immediate and replaced with recovery back to normal erectile function usually slow. Erectile dysfunction following radical prostatectomy is attributable primarily to nerve injury caused by intraoperative nerve traction, heat-induced injury, ischemic injury, and local inflammatory reactions [3].

There are limited studies evaluating the testosterone (Te) and gonadotropin levels in patients who have undergone radical prostatectomy for clinically localized PCa. The few previous studies have shown conflicting results on the changes in hormonal serum concentrations caused by rapid prostatectomy [8] 
[9]. It is well established that androgens, specifically $\mathrm{Te}$, are essential for prostate development [10]. Other studies have also shown that low Te serum levels was associated with undifferentiated tumors, advanced tumor stage and unfavorable prognosis after radical prostate surgery [11] [12] [13]. Furthermore, it is reported that serum concentration of total Te might affect sexual function after rapid prostatectomy (RP) for PCa [14]. It is also established that luteinizing hormone ( $\mathrm{LH})$ and follicle stimulating hormone (FSH) are involved in enhancing the production of androgens by stimulation of Leydig cells to produce testosterone and the production of androgen-binding protein by the Sertoli cells of the testes respectively [15]. These studies suggest that the role of serum concentrations of reproductive hormones, including the androgens and gonadotropins in the level of sexual functions of patients with PCa before and after RP, is far from being completely understood and requires further investigation. To date, no studies have evaluated the relationship of reproductive hormones with sexual functions of PCa patients in the post-operative period following RP. The aim of the present study was to evaluate the serum profile of postoperative reproductive hormones and their correlation with the post-operative sexual functions in the months following RP for patients with clinically localized PCa.

\section{Methodology}

A total of 20 male patients who underwent RP for biopsy proven and clinically localized PCa, at the Urology Clinic, Central Hospital, Benin City, Nigeria, for a post-operative period spanning from 1 to 12 months (between October, 2018 to November, 2019) were invited to participate in the post-operative study. Exclusion criteria included previous or current use of Te replacement therapy or hormonal manipulation, history of endocrine diseases, including hypogonadism, presence of systemic diseases such as diabetes mellitus and cardiovascular conditions, current use of a vesical catheter and chemotherapy or radiotherapy for treatment of pelvic neoplasia, chronic ingestion of alcohol or other drugs, that may interfere with the serum hormone levels. Informed consents were obtained from each participant after proper notification and information on the nature of the research, the benefits and risks involved as well as confidentiality. Ethics and research committee of Ministry of Health, Benin City approved this work with reference number HM.1208/7458.

Men fulfilling the inclusion criteria were interviewed using structured questionnaires. Demographic characteristics and detailed medical history, particularly about chronic systemic diseases, smoking and drinking habits, age at first sexual intercourse, urinary tract symptoms, current medications, family history of RP, pre and post-operative rating of mood/emotional state after surgery, frequency of sexual intercourse, rating of libido and erectile function were obtained from all patients. The rating of mood/emotional state of patients was structured to reflect the pattern shown in the Zung Self-Rating Depression Scale, a 20-item self-report questionnaire that is widely used as a screening tool, covering affec- 
tive, psychological and somatic symptoms associated with depression [16]. Each item is scored on a Likert scale ranging from 1 to 4 . A total score is derived by summing the individual item scores, and ranges from 20 to 80 . The scores range from 25 - 49 for Normal Range; 50 - 59 for Mildly Depressed; 60 - 69 for Moderately Depressed; and 70 and above for Severely Depressed. After the interview, the patients were sent to the laboratory to have a blood sample drawn in order to assess their reproductive hormonal levels for biochemical analysis.

\subsection{Biochemical Analysis}

Blood samples were collected by venopuncture between 8:00 and 11:00 a.m to assess the serum levels of prostate specific antigen (PSA), total Te (normal range: $3.0-10.0 \mathrm{ng} / \mathrm{ml}$ ) [17], FSH (Range: $1.4-18.1 \mathrm{mIU} / \mathrm{ml}$ ) and LH (Range: 1.5 - 9.3 $\mathrm{mIU} / \mathrm{ml}$ ) [18]. Serum levels of total Te, LH and FSH were determined by ELISA method using Calbiotech kits (Te, LH and FSH, CA 92020, USA), according to manufacturer's instructions.

\subsection{Data Analysis}

Data was expressed as mean \pm standard deviation or for continuous data and percentages for categorical variables. Test of normal distribution was done using the Kolmogorov Smirnov test. Comparative analysis between variables were done using independent sample t-test for data with normal distribution, while those without normal distribution were done using non-parametric Mann-Whitney U test. Comparative analysis involving categorical data was done using Chi-square comparative test. Correlation tests involving two variables were done using non-parameteric Spearman Ranking test. Test of significance was set at $\mathrm{p}<0.05$. All statistics were done using SPSS/IBM Software (version 20), while the size effects and statistical power were determined using the "G" Power software.

\section{Results}

The demographic and post-operative clinical characteristics of the study population are expressed in Table 1. The study consisted of 20 men with a mean age of 73.9 years (range: 53 - 85 years). The subjects were non-smokers, non-drinkers and all married. Majority of the patients had their first sexual experience at $>20$ years of age (70\%), had difficulty urinating (95\%), did not have the presence of blood in their urine (95\%), had no family history of prostatectomy (65\%). A greater percentage $(80 \%)$ of the patients indicated they were not depressed; most of the patients (85\%) stated they had poor libido and a greater percentage (45\%) rarely had sex.

Table 2 shows the post-operative clinical and hormonal characteristics of the study population. Data shows that at the time of assessment, most of the patients were "not depressed" (80\%), "unable to have sexual intercourse" (70\%), had poor libido (70\%), had "weak penile erection" (75\%), had PSA value of $0-2.4$ $\mathrm{ng} / \mathrm{ml}(70 \%)$. The results of the laboratory analyses of post-operative PSA, 
Table 1. Demographic and baseline characteristics of the study population $(n=20)$.

\begin{tabular}{|c|c|}
\hline Characteristics & $\begin{array}{c}\text { Value } \\
\text { Mean } \pm \text { SD or } n(\%)\end{array}$ \\
\hline Age (yrs) & $73.9 \pm 8.8$ \\
\hline \multicolumn{2}{|l|}{ Occupation } \\
\hline Businessmen & $1(5.0)$ \\
\hline Civil Servants & $5(25.0)$ \\
\hline Farmers & $1(5.0)$ \\
\hline Retirees & $13(65.0)$ \\
\hline \multicolumn{2}{|l|}{ Marital Status } \\
\hline Married & $20(100)$ \\
\hline Single & $0(0)$ \\
\hline \multicolumn{2}{|l|}{ Smoking Habit } \\
\hline Smokers & $0(0)$ \\
\hline Non-smokers & $20(100)$ \\
\hline \multicolumn{2}{|l|}{ Drinking Habit } \\
\hline Current Drinkers & $0(0)$ \\
\hline Non-drinkers & $20(100)$ \\
\hline \multicolumn{2}{|l|}{ Age of $1^{\text {st }}$ Sexual Intercourse } \\
\hline$\leq 20 y r s$ & $5(25.0)$ \\
\hline$>20 y r s$ & $14(70.0)$ \\
\hline Can't Remember & $1(5.0)$ \\
\hline \multicolumn{2}{|l|}{ Difficulty Urinating } \\
\hline No & $1(5.0)$ \\
\hline Yes & $19(95.0)$ \\
\hline \multicolumn{2}{|l|}{ Presence of Blood Urine } \\
\hline No & $19(95.0)$ \\
\hline Yes & $1(5.0)$ \\
\hline \multicolumn{2}{|l|}{ Family History Prostatectomy } \\
\hline No & $13(65.0)$ \\
\hline Yes & $6(30.0)$ \\
\hline No Idea & $1(5.0)$ \\
\hline \multicolumn{2}{|l|}{ Pre-operative Emotional Stability } \\
\hline Not Depressed & $16(80.0)$ \\
\hline Depressed & $4(20.0)$ \\
\hline \multicolumn{2}{|c|}{ Frequency of Sexual Intercourse (per month) } \\
\hline Zero (None) & $7(35.0)$ \\
\hline 1 - 2 times (Rarely) & $9(45.0)$ \\
\hline 3 - 4 times (Occasionally) & $3(15.0)$ \\
\hline$\geq 5$ times (Regular) & $1(5.0)$ \\
\hline \multicolumn{2}{|l|}{ Pre-operative Libido } \\
\hline Poor & $17(85.0)$ \\
\hline Fair & $0(0)$ \\
\hline Good & $3(15.0)$ \\
\hline
\end{tabular}

testosterone, FSH and $\mathrm{LH}$ are as shown in Table 2. Independent sample t-test indicated that no significant differences were observed in PSA, testosterone, FSH and LH levels $\leq 6$ months after RP as compared with $>6$ months post-operative. The Mann-Whitney $U$ tests also indicated no significant differences in mean 
Table 2. Post-operative clinical and hormonal characteristics of the study population.

\begin{tabular}{|c|c|c|c|c|c|}
\hline Patients' Characteristics & All, $\mathrm{n}=20$ & $\begin{array}{c}\leq 6 \text { Months } \\
\text { Post-Operative } \\
\text { Period, } n=11\end{array}$ & $\begin{array}{c}>6 \text { Months } \\
\text { Post-Operative } \\
\text { Period, } n=9\end{array}$ & $\begin{array}{l}\text { Size } \\
\text { Effect }\end{array}$ & P-Value \\
\hline Emotional State ${ }^{\ddagger}$ & & 12.50 & 8.06 & -2.17 & 0.016 \\
\hline Severely Depressed $d^{\dagger}$ & $0(0)$ & $0(0)$ & $0(0)$ & - & - \\
\hline Moderately Depressed ${ }^{\dagger}$ & $3(15.0)$ & $0(0)$ & $3(33.3)$ & - & - \\
\hline Mildly Depressed ${ }^{\dagger}$ & $1(5.0)$ & $0(0)$ & $1(11.1)$ & - & - \\
\hline Not Depressed & $16(80.0)$ & $11(100)$ & $5(55.6)$ & 12.41 & $<0.001$ \\
\hline Frequency of Sexual Intercourse (per month) & & 11.27 & 9.56 & -1.07 & 0.425 \\
\hline Zero $(\text { None })^{\dagger}$ & $14(70.0)$ & $7(63.6)$ & $7(77.8)$ & 1.38 & 0.240 \\
\hline $1-2$ times $\left(\right.$ Rarely) ${ }^{\dagger}$ & $2(10.0)$ & $1(9.1)$ & $1(11.1)$ & 0.20 & 0.655 \\
\hline 3 - 4 times (Occasionally) ${ }^{\dagger}$ & $3(15.0)$ & $2(18.2)$ & $1(11.1)$ & 1.69 & 0.194 \\
\hline$\geq 5$ times $(\text { Regular })^{\dagger}$ & $1(5.0)$ & $1(9.1)$ & $0(0)$ & - & - \\
\hline Libido ${ }^{\ddagger}$ & & 10.9 & 11.0 & -0.14 & 0.670 \\
\hline Poor $^{*}$ & $14(70.0)$ & $8(72.7)$ & $6(66.7)$ & 0.25 & 0.612 \\
\hline Fair $^{\dagger}$ & $1(5.0)$ & $1(9.1)$ & $0(0)$ & - & - \\
\hline Good $^{\dagger}$ & $5(25.0)$ & $2(18.2)$ & $3(33.3)$ & 4.41 & 0.036 \\
\hline Penile Erection ${ }^{\ddagger}$ & & 10.18 & 10.89 & -0.20 & 0.726 \\
\hline None $^{\dagger}$ & $1(5.0)$ & $1(9.1)$ & $0(0)$ & - & - \\
\hline$W e a k^{\dagger}$ & $15(75.0)$ & $8(72.7)$ & $7(77.8)$ & 0.25 & 0.684 \\
\hline Fairly Strong ${ }^{\dagger}$ & $2(10.0)$ & $0(0)$ & $2(22.2)$ & - & - \\
\hline Very Strong ${ }^{\dagger}$ & $2(10.0)$ & $2(18.2)$ & $0(0)$ & - & - \\
\hline PSA $(n g / m l)^{*}$ & $3.66 \pm 6.98$ & $3.35 \pm 6.88$ & $4.03 \pm 7.50$ & -0.34 & 0.836 \\
\hline $0-2.4^{\dagger}$ & $14(70.0)$ & $8(72.7)$ & $6(66.7)$ & 0.25 & 0.612 \\
\hline $2.5-3.9^{\dagger}$ & $0(0)$ & $0(0)$ & $0(0)$ & - & - \\
\hline $4-10.0^{\dagger}$ & $4(20.0)$ & $2(18.2)$ & $2(22.2)$ & 0.40 & 0.527 \\
\hline$>10.0^{\dagger}$ & $2(10.0)$ & $1(9.1)$ & $1(11.1)$ & 0.20 & 0.655 \\
\hline $\mathrm{Te}(\mathrm{ng} / \mathrm{ml})^{*}$ & $4.34 \pm 4.38$ & $3.20 \pm 4.60$ & $5.73 \pm 3.90$ & -0.83 & 0.207 \\
\hline $\mathrm{FSH}(\mathrm{mIU} / \mathrm{ml})^{*}$ & $39.24 \pm 34.12$ & $42.06 \pm 40.90$ & $35.80 \pm 25.50$ & -0.58 & 0.694 \\
\hline $\mathrm{LH}(\mathrm{mIU} / \mathrm{ml})^{*}$ & $21.67 \pm 25.73$ & $24.38 \pm 26.71$ & $18.35 \pm 25.65$ & 0.34 & 0.616 \\
\hline
\end{tabular}

Abbreviations: PSA, prostate specific antigen; Te, testosterone; FSH, follicle stimulating hormone; LH, Luteinizing hormone. ${ }^{\star}$ Mean $\pm \mathrm{SD}$; ${ }^{\dagger} \mathrm{n}(\%) ;{ }^{\ddagger}$ Mean Ranking of scores. Rating of self reported emotional state was scored on a Likert scale ranging from 1 to 4 (normal $=1$; mildly depressed $=2$; moderately depressed $=3$, severely depressed $=4)$. Rating of Libido was based on Likert scale $1-3($ poor $=1$, fair $=2$, good $=3$ ). Penile Erection score was based on Likert scale 1 - $4(1=$ none, weak $=2$, fairly strong $=3$, very strong $=4)$.

rankings of scores for all the sexual function parameters between the two postoperative periods. In contrast, patients who had RP in $\leq 6$ months period indicated significantly higher ( 12.50 vs. $8.06 ; \mathrm{p}=0.016)$ emotional state score compared with the $>6$ months period. Furthermore, Chi-square test indicated that the $\leq 6$ months post-operative group had significant higher incidence of "not depressed" emotional state ( $100 \%$ vs. $55.6 \%$; $\mathrm{p}<0.001)$, but lower incidence of "good libido" ( $18.2 \%$ vs. $33.3 \% ; \mathrm{p}=0.036)$ compared with the $>6$ months post-operative group. In contrast, no significant differences were observed in the incidences of the other clinical characteristics between the two groups.

Table 3: A bivariate correlation statistics using Spearman's Ranking test indicated that there was a positive correlation between Te and frequency of sexual intercourse $(r=508 ; p<0.05)$, libido $(r=0.429 ; p<0.05)$, penile erection $(r=$ 
Table 3. Bivariate correlations among reproductive hormonal levels, emotional state and sexual functions of the study population after rapid prostatectomy.

\begin{tabular}{|c|c|c|c|c|c|c|c|c|}
\hline Variables & TST & FSH & LH & Age & $\begin{array}{c}\text { Emotional } \\
\text { State }\end{array}$ & FSI & Libido & Erection \\
\hline $\mathrm{Te}$ & 1.00 & -0.008 & -0.058 & 0.116 & -0.028 & $0.508^{*}$ & $0.429^{*}$ & $0.494^{\star}$ \\
\hline FSH & & 1.00 & $0.555^{\star}$ & 0.217 & -0.199 & -0.041 & -0.020 & 0.163 \\
\hline LH & & & 1.00 & -0.258 & -0.095 & 0.037 & -0.298 & 0.045 \\
\hline Age & & & & 1.00 & -0.334 & -0.363 & -0.149 & -0.032 \\
\hline $\begin{array}{l}\text { Emotional } \\
\text { Stability }\end{array}$ & & & & & 1.00 & 0.320 & 0.026 & 0.170 \\
\hline FSI & & & & & & 1.00 & $0.593^{\star *}$ & $0.755^{\star * *}$ \\
\hline Libido & & & & & & & 1.00 & $0.763^{\star * *}$ \\
\hline Erection & & & & & & & & 1.00 \\
\hline
\end{tabular}

Abbreviations: Te, testosterone; FSH, follicle stimulating hormone; LH, Luteinizing hormone; FSI, frequency of sexual intercourse. Data are presented as Spearman's rank correlations; $\mathrm{n}=20 ;{ }^{*} \mathrm{p}<0.05 ;{ }^{* *} \mathrm{p}<$ $0.01 ;{ }^{* * *} \mathrm{p}<0.001$.

0.494; $\mathrm{p}<0.05)$. However, no significant correlations were found between FSH or LH and any of the sexual function parameters (FSI, libido and erection). Interactions among the reproductive hormones indicated significant positive correlation between FSH and $\mathrm{LH}(\mathrm{r}=0.555 ; \mathrm{p}<0.05)$. In contrast, no significant correlations were observed between Te and LH or FSH. Age did not show any significant relationships with any of the reproductive hormones, emotional state or sexual functions of the patients. Similarly, the emotional state of the patients had no correlations with their reproductive hormonal levels or sexual functions. Interactions among the sexual functions of the patients indicated significant positive correlations between frequency of sexual intercourse and libido $(r=$ 0.593; $\mathrm{p}<0.01)$ and penile erection $(\mathrm{r}=0.755 ; \mathrm{p}<0.001)$. Furthermore, a positive significant correlation was observed between libido and penile erection $(\mathrm{r}=$ $0.763 ; \mathrm{p}<0.001)$.

Multiple linear regression analysis adjusted for age and emotional state, was performed to assess the influence of each of the reproductive hormones $(\mathrm{Te}$, FSH, LH) on the post-operative sexual functions of the patients (Table 4). The $\mathrm{t}$-statistics showed that, of the three hormones, Te had the strongest associations with the frequency of sexual intercourse ( $\mathrm{t}$-statistics, 3.51; $\mathrm{p}<0.01$ ), libido ( $\mathrm{t}$-statistics, 2.26; $\mathrm{p}<0.05$ ) and penile erection ( $\mathrm{t}$-statistics, 2.73; $\mathrm{p}<0.05$ ).

\subsection{Discussion}

The present study indicated normal levels of post-operative Te in the patients following RP, while the mean levels of FSH and LH were on the increase and far above normal ranges for healthy men. Our data indicated a mean testosterone level of $4.34 \mathrm{ng} / \mathrm{ml}$, mean FSH level of $39.24 \mathrm{mIU} / \mathrm{ml}$ and mean $\mathrm{LH}$ level of 21.63 $\mathrm{mIU} / \mathrm{ml}$. Published normal ranges in healthy men for serum testosterone concentrations is $3.0-10.0 \mathrm{ng} / \mathrm{ml}$ [17], while those of serum LH and FSH 
Table 4. Age and emotional state adjusted correlation between post-operative reproductive hormonal levels and sexual functions of patients.

\begin{tabular}{cccccccccc}
\hline & \multicolumn{3}{c}{ Frequency of } & \multicolumn{3}{c}{ Libido } & \multicolumn{3}{c}{ Penile Erection } \\
Variables & \multicolumn{3}{c}{ Sexual Intercourse } & \multicolumn{3}{c}{ c } \\
\cline { 2 - 10 } & $\mathrm{R}$ & t-statistics & p-value & $\mathrm{R}$ & t-statistics & p-value & $\mathrm{R}$ & t-statistics & p-value \\
\hline $\mathrm{Te}$ & 0.590 & 3.51 & 0.003 & 0.520 & 2.26 & 0.040 & 0.565 & 2.73 & 0.016 \\
$\mathrm{FSH}$ & 0.176 & 0.92 & 0.370 & -0.063 & -0.24 & 0.810 & 0.061 & 0.26 & 0.798 \\
$\mathrm{LH}$ & -0.190 & -0.99 & 0.336 & -0.124 & -0.476 & 0.642 & 0.090 & 0.38 & 0.708 \\
\hline
\end{tabular}

Abbreviations: Te, testosterone; FSH, follicle stimulating hormone; LH, Luteinizing hormone; $r$, correlation coefficient.

concentrations are typically $1.4-18.1 \mathrm{miu} / \mathrm{ml}$ and $1.5-9.3 \mathrm{miu} / \mathrm{ml}$ respectively [18]. A previous study by Madersbacher et al. [8] has shown a similar value in Te (4.4 ng/ml), but lower values in FSH $(9.3 \mathrm{miu} / \mathrm{ml})$ and $\mathrm{LH}(8.9 \mathrm{miu} / \mathrm{ml})$ after RP in patients with PCa. Similarly, Namiki et al. [19] reported higher values of Te $(12.9 \mathrm{ng} / \mathrm{ml})$ and lower values of $\mathrm{LH}(5.53 \mathrm{miu} / \mathrm{ml}$ at $3 \mathrm{months}$ and $6.87 \mathrm{miu} / \mathrm{ml}$ at 12 months after RP in PCa patients. Another study [20] indicated higher values of Te at $1^{\text {st }}$ and $3^{\text {rd }}$ months $(13.8 \mathrm{ng} / \mathrm{ml}$ and $14.4 \mathrm{ng} / \mathrm{ml})$ after RP. It has been previously reported that surgical intervention for prostate cancer causes a reduction in the testicular production of Te at the onset, which will stimulate an increase in production of gonadotropins by negative feedback, and later resulting in recovery or normalization of the Te level [20]. This may provide a possible explanation for the surge in post-operative LH and FSH levels accompanied by a corresponding normal serum Te that fell within normal range in this study.

No significant differences were observed in Te, LH and FSH levels between $>6$ months and $\leq 6$ months postoperative periods, although the mean serum concentrations appeared greater in LH and FSH, but lower in Te at $>6$ months period as compared with $\leq 6$ months period after RP. Previous studies have shown increased gonadotropin levels with normal Te levels at 6 and 12 months following RP [8] [9]. However, the postoperative evaluation in the present study considered postoperative periods from 1 - 6 months and compared them with periods greater than 6 months. The higher increase in values observed in levels of gonadotropins at $>6$ months after RP in this study, appears to delineate the features of compensatory hypergonadotropic negative feedback mechanism. It is noteworthy that there were no significant differences observed in the mean rankings of the postoperative sexual functions of the patients. This may be a reflection of the lack of significant differences observed in the concentrations of the reproductive hormones. However, the higher incidence of "good" libido observed in patients $\leq 6$ months after RP may be associated with the significantly normal emotional state observed in these patients compared with those of $>6$ months after RP (Table 2).

There are limited studies examining the association between sex hormone serum levels and sexual functions among PCa patients after RP. The present study 
suggests that androgen levels may exert a significant influence on sexual functions in PCa patients after RP. This is evident in the significant correlations observed between frequency of sexual intercourse, erectile function, sex drive and Te in this study. Of the three reproductive hormones (Te, LH, FSH) studied, Te also appeared to be the strongest predictor of the sexual functions. The relationship of testosterone levels with sexual activity in older men has been controversial [21] [22] [23] [24]. Some of the studies [21] [22] [23] reported a significant positive correlation between levels of sexual activity and serum testosterone levels in healthy older men aged above 40 years. Marberger et al. [24] on the other hand demonstrated that Te was not a significant independent predictor of sexual dysfunction among patients with prostate cancer. However, it is not known if a positive correlation between Te and sexual functions has been demonstrated in any previous study involving older men with PCa who underwent RP. The present finding may justify the choice of testosterone replacement therapy in older PCa patients with sexual dysfunction.

It is established that gonadotropic hormones, LH and FSH are involved in enhancing the production of androgens by stimulation of Leydig cells to produce testosterone and the production of androgen-binding protein by the Sertoli cells of the testes respectively [15]. Against expectations, LH and FSH did not exert any significant influence on either Te or sexual functions in the present study. To the best of our knowledge, no studies are found in literature investigating the relationship between the gonadotropic hormones and sexual functions in PCa patients after RP. Studies have mostly demonstrated that sexual health after RP is strongly dependent on patient's age, aging, tumor characteristics, depression, distress and disease progression [5] [25] [26]. Furthermore, a previous study found a remarkable positive correlation between $\mathrm{T}$ and LH before surgery, but not after RP [27]. These present findings therefore suggest that gonadotropic hormones, LH and FSH, may not play any significant roles in the sexual dysfunctions associated with radical prostatectomy. Furthermore, the observed influence of Te on sexual functions appears independent of the influence of the $\mathrm{LH}$ and FSH levels during the postoperative period.

A potential limitation of the present study is that the study sample size was relatively small and we could not measure the preoperative baseline values of the hormone for further comparative analysis.

\subsection{Conclusion}

This study indicated that radical prostatectomy affects reproductive hormones by increasing LH and FSH concentrations, while Te concentrations remain stable after surgery. Postoperative total Te concentrations are significantly associated with the postoperative sexual functions after RP and appear to be the strongest predictor for sexual function compared with LH and FSH. These findings may have clinical implications for the treatment of sexual dysfunction in prostate cancer patients who underwent RP. 


\section{Acknowledgements}

The authors acknowledge the Ethics and Research Committee of Ministry of Health, Edo state and all the participants.

\section{Funding}

The research was privately funded. No grant or sponsorship from anywhere.

\section{Conflicts of Interest}

The authors declare no conflicts of interest regarding the publication of this paper.

\section{References}

[1] Bray, F., Ferlay, J., Soerjomataram, I., Siegel, R.L., Torre, L.A. and Jemal, A. (2018) Global Cancer Statistics 2018: GLOBOCAN Estimates of Incidence and Mortality Worldwide for 36 Cancers in 185 Countries. CA: A Cancer Journal for Clinicians, 68, 394-424. https://doi.org/10.3322/caac. 21492

[2] Ferlay, J.E.M., Lam, F., Colombet, M., Mery, L., Pineros, M., Znaor, A., Soerjomataram, I., et al. (2020) Global Cancer Observatory: Cancer Today. International Agency for Research on Cancer, Lyon. https://gco.iarc.fr/today

[3] Hyun, J.S. (2012) Prostate Cancer and Sexual Function. The World Journal of Men's Health, 30, 99-107. https://doi.org/10.5534/wjmh.2012.30.2.99

[4] Moore, T.M., Strauss, J.L., Herman, S. and Donatucci, C.F. (2003) Erectile Dysfunction in Early, Middle, and Late Adulthood: Symptom Patterns and Psychosocial Correlates. Journal of Sex \& Marital Therapy, 29, 381-997.

https://doi.org/10.1080/00926230390224756

[5] Nelson, C.J., Mulhall, J.P. and Roth, A.J. (2011) The Association between Erectile Dysfunction and Depressive Symptoms in Men Treated for Prostate Cancer. The Journal of Sexual Medicine, 8, 560-566. https://doi.org/10.1111/j.1743-6109.2010.02127.x

[6] Signy, H. (Ed.) (2014) Understanding Sexual Issues Following Prostate Cancer Treatment. Prostate Cancer Foundation of Australia. http://www.prostate.org.au/media/468674/understanding-sexual-issues.pdf

[7] McCullough, A.R. (2005) Sexual Dysfunction after Radical Prostatectomy. Reviews in Urology, 7, S3-S10.

[8] Madersbacher, S., Schatzl, G., Bieglmayer, C., et al. (2002) Impact of Radical Prostatectomy and TURP on the Hypothalamic-Pituitary-Gonadal Hormone Axis. Urology, 60, 869-874. https://doi.org/10.1016/S0090-4295(02)01893-9

[9] Miller, L.R., Partin, A.W., Chan, D.W., et al. (1998) Influence of Radical Prostatectomy on Serum Hormone Levels. Journal of Urology, 160, 449-453. https://doi.org/10.1016/S0022-5347(01)62922-7

[10] Reiter, R.E. and de Kernion, J.B. (2002) Epidemiology, Etiology, and Prevention of Prostate Cancer. In: Walsh, P.C., Ed., Campbell s Urology, 8th Edition, Saunders, Philadelphia, 3003.

[11] Massengill, J.C., Sun, L., Moul, J.W., Wu, H., McLeod, D.G., Amling, C., et al. (2003) Pretreatment Total Testosterone Level Predicts Pathological Stage in Patients with Localized Prostate Cancer Treated with Radical Prostatectomy. Journal of Urology, 169, 1670-1676. https://doi.org/10.1097/01.ju.0000062674.43964.d0 
[12] Morgentaler, A., Bruning 3rd, C.O. and DeWolf, W.C. (1996) Occult Prostate Cancer in Men with Low Serum Testosterone Levels. JAMA, 276, 1904-1906. https://doi.org/10.1001/jama.1996.03540230054035

[13] Yamamoto, S., Yonese, J., Kawakami, S., Ohkubo, Y., Tatokoro, M., et al. (2007) Preoperative Serum Testosterone Levels as an Independent Predictor of Treatment Failure Following Radical Prostatectomy. European Urology, 52, 696-701. https://doi.org/10.1016/j.eururo.2007.03.052

[14] Khera, M. (2009) Androgens and Erectile Function: A Case for Early Androgen Use in Postprostatectomy Hypogonadal Men. Journal of Sexual Medicine, 6, 234-238. https://doi.org/10.1111/j.1743-6109.2008.01159.x

[15] Corradi, P.F., Corradi, R.B. and Greene, L.W. (2016) Physiology of the Hypothalamic Pituitary Gonadal Axis in the Male. Urologic Clinics of North America, 43, 151-162. https://doi.org/10.1016/j.ucl.2016.01.001

[16] Zung, W.W. (1965) A Self-Rating Depression Scale. Archives of General Psychiatry, 12, 63-70. https://doi.org/10.1001/archpsyc.1965.01720310065008

[17] Griffin, J.E. and Wilson, J.D. (1998) Disorders of the Testes. In: Fauci, A.S., Martin, J.B., Braunwald, E., Kaspar, D.L., Isselbacher, K.J. and Hauser, S.I., Eds., Harrison's Principles of Internal Medicine, McGraw-Hill, New York, 2087-2097.

[18] Schmitt, C.S., Rhoden, E.L. and Almeida, G.L. (2011) Serum Levels of Hypothalamic-Pituitary-Testicular Axis Hormones in Men with or without Prostate Cancer or Atypical Small Acinar Proliferation. Clinics, 66, 183-187. https://doi.org/10.1590/S1807-59322011000200001

[19] Namiki, S., Mitsuzuka, K., Kaiho, Y., Yamada, S., Adachi, H., Yamashita, S., Saito, H., Ito, A., Nakagawa, H., Takegami, M. and Ara, Y. (2016) Serum Luteinizing Hormone Concentration Is Significantly Associated with Recovery of Urinary Function after Radical Prostatectomy. BJU International, 117, 450-455. https://doi.org/10.1111/bju.13083

[20] Gacci, M., Tosi, N., Vittori, G., Minervini, A., Corona, G., Cai, T., Morelli, A.M., Vignozzi, L., Serni, S., Maggi, M. and Carini, M. (2013) Changes in Sex Hormone Levels after Radical Prostatectomy: Results of a Longitudinal Cohort Study. Oncology Letters, 6, 529-533. https://doi.org/10.3892/ol.2013.1420

[21] Tsitouras, P.D., Martin, C.E. and Harman, S.M. (1982) Relationship of Serum Testosterone to Sexual Activity in Healthy Elderly Men. Journal of Gerontology, 37, 288-293. https://doi.org/10.1093/geronj/37.3.288

[22] Gades, N.M., Jacobson, D.J., McGree, M.E., et al. (2008) The Associations between Serum Sex Hormones, Erectile Function, and Sex Drive: The Olmsted County Study of Urinary Symptoms and Health Status among Men. Journal of Sexual Medicine, 5, 2209-2220. https://doi.org/10.1111/j.1743-6109.2008.00924.x

[23] O'Connor, D.B., Lee, D.M., Corona, G., et al. (2011) The Relationships between Sex Hormones and Sexual Function in Middle-Aged and Older European Men. The Journal of Clinical Endocrinology \& Metabolism, 96, E1577-E1587.

[24] Marberger, M., Wilson, T.H. and Rittmaster, R.S. (2011) Low Serum Testosterone Levels Are Poor Predictors of Sexual Dysfunction. BJU International, 108, 256-262. https://doi.org/10.1111/j.1464-410X.2010.09766.X

[25] Hoppe, B.S., Nichols, R.C., Henderson, R.H., Morris, C.G., Williams, C.R., Costa, J., et al. (2012) Erectile Function, Incontinence, and Other Quality of Life Outcomes Following Proton Therapy for Prostate Cancer in Men 60 Years Old and Younger. Cancer, 118, 4619-4626. https://doi.org/10.1002/cncr.27398

[26] Helgason, A.R., Adolfsson, J., Dickman, P., Fredrikson, M., Arver, S. and Steineck, 
G. (1996) Waning Sexual Function-The Most Important Disease-Specific Distress for Patients with Prostate Cancer. British Journal of Cancer, 73, 1417-1421. https://doi.org/10.1038/bjc.1996.268

[27] Lackner, J.E., Maerk, I., Koller, A., et al. (2008) Serum Inhibin-Not a Cause of Low Testosterone Levels in Hypogonadal Prostate Cancer? Urology, 72, 1121-1124. https://doi.org/10.1016/j.urology.2008.01.066 